Published by LPMP Imperium

Journal homepage: https://ejournal.imperiuminstitute.org/index.php/JMSAB

\section{Stres kerja dan cybeloafing pada generasi Y dan Z: Peran usia dan status pernikahan sebagai boundary condition}

\section{Achmadi}

Sekolah Tinggi Ilmu Ekonomi Tunas Nusantara, Jakarta

\begin{abstract}
Using the transactional stress and border theory framework model, we explore the relationship between job stress and cyberloafing by placing biographies (age and marital status) as boundary conditions. An online questionnaire involved a total of 182 employees in this study. The analysis results using moderated hierarchical regression indicate that work stress has a positive and significant effect on cyberloafing behavior. In the moderation model, this study only proved that age was significant as a moderator in the relationship between job stress and cyberloafing, but not for marital status. In addition, age and marital status were not potential predictors of cyberloafing. Implications and suggestions are described in the article.
\end{abstract}

\begin{abstract}
Abstrak
Menggunakan kerangka model transaksional stress dan border theory, studi ini mengeksplorasi hubungan stres kerja dan cyberloafing dengan menempatkan biografis (usia dan status pernikahan) sebagai kondisi batas. Sebanyak 182 orang karyawan yang terlibat dalam studi ini melalui kuesioner online. Hasil analisis menggunakan regresi hierarki moderasi bahwa stres kerja terbukti memiliki pengaruh positif dan signifikan terhadap perilaku cyberloafing. Pada model moderasi, studi ini hanya berhasil membuktikan bahwa usia signifikan sebagai pemoderasi pada hubungan stres kerja dan cyverloafing, namun tidak untuk status pernikahan. Selain itu, usia dan status pernikahan bukanlah indikator potensial dari cyberloafing. Implikasi dan saran dijelaskan dalam artikel.
\end{abstract}

*Email korespondensi: achmadi@stietn.ac.id

Pedoman Achmadi, A. (2021). Stres kerja dan cybeloafing pada generasi Y dan Z: Peran usia dan status pernikahan sebagai boundary condition. Jurnal Manajemen Strategi Dan Aplikasi Bisnis, 4(2), 461 470 .
JMSAB

\section{1}

Paper type

Researh Paper

Keywords: job stress, cyberloafing, age, marital status

Received: 14 Jul 2021

Revised: 18 Nov 2021

Accepted: 28 Nov 2021

Online: 08 Dec 2021

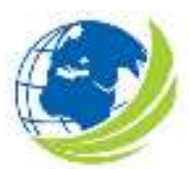

Jurnal Manajemen Strategi dan Aplikasi Bisnis, Vol 4, No.2, 2020, pp. $461-470$ eISSN 2655-237X 


\section{PENDAHULUAN}

Perkembangan Teknologi Informasi dan Internet merupakan salah satu perubahan paling signifikan dalam sepuluh tahun terakhir. Bahkan, teknologi internet sekarang telah menjadi bagian tak terpisahkan dan memberikan kemanfaatan yang besar bagi individu maupun bisnis (Hunady et al., 2020). Seiring konsekuensi positif nya, berbagai dampak buruk yang ditimbulkan oleh aktivitas internet di tempat kerja juga meningkat. Para peneliti di bidang manajemen mencatat salah satu yang paling mengganggu adalah cyberloafing dimana karyawan menggunakan jaringan internet untuk keperlun pribadi. Berdasarkan laporan sebuah survey di Amerika tahun 2017 - 2018, kerugian akibat cyberloafing mencapai USD 85 miliar dalam satu tahun dan menyebabkan penurunan produktivitas sebesar 30 - 40 persen (Chavan et al., 2021; Kim 2018; Kim et al., 2016).

Cyberloafing dianggap sebagai ancaman hampir semua organisasi karena sebagian besar aktvitas kerja karyawan menggunakan perangkat teknologi informasi sehingga kesempatan untuk terlibat sangat besar. Para peneliti kemudian berupaya untuk memahami lebih lanjut mengenai persepsi karyawan mengenai cyberloafing, dan menariknya, isu cyberloafing sering dikaitkan dengan generasi milenial (generasi $\mathrm{Y}$ ) dan setelahnya (generasi $\mathrm{Z}$ ) yang memang lahir di masa teknologi smartphone, laptop, dan media social (Yui et al., 2021). Karena terbiasa beraktivitas menggunakan perangkat teknologi informasi, generasi $\mathrm{Y}$ dan $\mathrm{Z}$ dianggap memiliki kemampuan menggunakan teknologi yang lebih baik dibandingkan generasi sebelumnya. Meskipun demikian, Mercado et al. (2017) berpendapat bahwa investigasi cyberloafing masih dalam tahap awal sehingga mereka mendorong para peneliti untuk lebih memahami cyberloafing antara generasi dan kelompok tertentu.

Meskipun sebagai peneliti menganggap bahwa cyberloafing dapat merugikan perusahaan, namun temuan terbaru menemukan bahwa cyberloafing bukanlah tindakan berbahaya. Misalnya Koay dan Soh (2019) melaporkan dalam sebuah meta analisis menemukan bahwa dampak cyberloafing pada kinerja tidak dapat disimpulkan dan berbagai penelitian menemukan hasil yang beragam. Dengan kata lain, penelitian di bidang ini menemukan bahwa cyberloafing dapat berdampak positif, negatif atau tidak signifikan terhadap prestasi kerja. Sebelumnya, Mercado et al. (2017) melaporkan bahwa cyberloafing dapat dianggap sebagai perilaku kontraproduktif namun efek yang ditimbulkannya tidak memiliki efek signifikan pada komponen kinerja. Cyberloafing bahkan dianggap oleh generasi milenia sebagai alat mereka untuk bekerja lebih cepat, untuk mengurangi kebosanan dan stress di tempat kerja. Mayoritas responden pun memandang bahwa perilaku tidak salah, sudah menjadi kebiasaan, dan justru sebagai kebutuhan untuk dapat bersaing di masa sekarang ini. Disisi lain, para peneliti menemukan efek positif cyberloafing sebagai mekanisme koping untuk mengurangi rasa bosan (Pindek et al., 2018), meminimalkan stress akibat perilaku kurang menyenangkan di tempat kerja (Andel et al., 2019; Koay et al., 2017), dan bahkan terkait dengan perilaku inovatif karyawan (Derin \& Gökçe, 2016). Dengan demikian, efek negatif cyberloafing dalam kaitannya dengan perilaku kerja karyawan masih membutuhkan eksplorasi lebih lanjut dan terbuka untuk diteliti ulang.

Sudi ini secara khusus menanggapi Mercado et al. (2017) untuk memeriksa persepsi generasi milenial tentang cyberloafing di tempat kerja, khususnya dalam konteks Indonesia. Selain itu, studi di arahkan untuk menguju hubungan antara stres kerja dan cyberloafing dengan menempatkan karakteristik individu (usia dan status pernikahan) sebagai kondisi batas (boundary condition). Berbeda dengan studi sebelumnya yang lebih banyak mengarahkan pada konsekuensi cyberloafing (Derin \& Gökçe, 2016; Koay dan Soh, 2019), penyebabnya (Andel et al., 2019; Koay et al., 2017; Pindek et al., 2018), dan atau keduanya (Koay et al., 2017), studi ini 
diarahkan untuk menguji mekanisme proses dimana pengaruh stres kerja terhadap cberyloafing dan perilaku kreatif karyawan akan dimoderasi oleh karakteristik biografis yaitu usia dan status pernikahan. Dengan demikian, studi ini akan memberikan wawsan baru mengenai model hubungan stres kerja dan cyberloafing karyawan dengan menempatkan usia dan status pernikahan sebagai boundary condition.

\section{KAJIAN PUSTAKA}

Teori perbatasan (Border Theory) yang dikembangkan oleh Clark (2000) dapat menjelaskan bagaimana individu yang melintasi batas untuk memenuhi kebutuhan pekerjaan dan nonpekerjaan mereka secara bersamaan. Kedua kebutuhan tersebut baik pekeraan dan nonpekerjaan memilki peran yang sama-sama penting sehingga individu memiliki kencerungan untuk melintasi batas sehingga kebutuhan keduanya terpenuhi (Konig dan Caner de la Guardia, 2014), sehingga cyberloafing merupakan sarana transisi. Sebagai contoh, seorang karyawan dapat mengatur pertemuan dengan teman-temannya, atau karyawawn perempuan yang membantu tugas sekolah anaknya saat jam kerja. Teori ini memberikan gambaran kemampuan seseorang untuk secara bersamaan memegang peran ganda sehingga upaya memenuhi tuntutan keduanya menjadi sering bersilangan (Konig dan Caner de la Guardia, 2014).

Di sisi lain, cyberloafing juga dapat dijelaskan melalui transactional model of stress (Lazarus \& Folkman, 1984) memberikan kerangka berpikir bahwa perilaku cyberloafing merupakan mekanisme koping untuk mengurangi stres kerja. Mekanisme koping merupakan cara yang dilakukan oleh individu untuk menangani situasi stres. Strategi ini sendiri dikelompokkan menjadi dua yaitu strategi koping yang berfokus pada masalah dan yang berfokus pada emosi (Lazarus \& Folkman, 1984). Strategi koping yang berfokus pada masalah lebih dikatikan dengan upaya untuk menghilangkan stres melalui bantuan orang lain. Contohnya adalah meminta bantuan teman untuk memberikan saran dan masukan pada masalah yang terkait pekerjaan. Sedangkan strategi koping yang berfokus pada emosi lebih mengarah pada pengelolaan emosi pada situasi stres. Misalnya, seseorang menonton video yang dapat menghibur dan mengembalikan mood nya ketika bekerja.

\section{Stres kerja dan cyberloafing}

Cyberloafing merupakan fenomena dimana karyawan menggunakan internet untuk keperluan pribadi selama jam kerja (Rahimnia dan Mazidi, 2015). Konsep cyberloafing memiliki banyak perspektif, dan salah satunya di perkenalkan oleh Lim (2002) yang menjelaskan taksonomi cyberloafing. Dalam tulisannya, Lim menyatakan bahwa cyberloafing terdiri dari dua faktor yaitu penjelajahan web dan email. Mahatanankon et al. (dalam Ozler \& Polat, 2012) mengelompokkan cyberloafing ke dalam bentuk: e-commerce, informasi riset dan komunikasi pribadi. Taksonomi lain diusulkan oleh Mastrangelo et al (2006) sebagai perilaku nonproduktif penggunaan komputer dan penggunaan komputer yang kontraproduktif.

Sejalan dengan Henle dan Blanchard (2008) yang menggunakan taksonomi koping Lazarus dan Folkman (1984), studi ini juga mengusulkan bahwa cyberloafing merupakan bentuk lain dari koping yang berfokus pada emosi. Mereka mengemukakan bahwa berfokus pada tugastugas yang tidak terkait dengan pekerjaan melalui cyberloafing memungkinkan karyawan untuk secara psikologis melepaskan diri dari efek negatif stresor di tempat kerja. Bukti empiris mendukung postulat ini; karyawan yang mengalami stresor pekerjaan, seperti harapan kerja yang ambigu atau bertentangan, terlibat dalam cyberloafing sebagai bentuk pelarian, koping yang berfokus pada emosi (Henle \& Blanchard, 2008). Hasil serupa juga baru-baru ini ditemukan dalam 
sebuah penelitian oleh Pindek et al. (2018), menunjukkan bahwa karyawan terlibat dalam cyberloafing untuk mengatasi pengalaman kerja yang membuat stres. Studi ini dalam posisi mendukung pernyataan Chavan et al. (2021) dan Mercado et al. (2017) yang memposisikan cyberloafing sebagai mekanisme coping dan berhubungan dengan emosi. Dengan demikian hipotesis yang diajukan adalah:

H1. Stres kerja berpengaruh positif terhadap perilaku cyberloafing

\section{Peran usia dan status pernikahan terhadap hubungan stres kerja dan cyberloafing}

Koay et al. (2017) dalam meta analisisnya memberikan berbagai kesimpulan bahwa predictor cyberloafing dapat berupa kebosanan, keterlibatan, dan pengendalian diri, tetapi sikap karyawan di sekitar dan peluang untuk terlibat dalam cyberloafing juga terbukti sebagai prediktor yang kuat. Meski demikian, hasil studi mereka menemukan bahwa usia dan variabel demografis lainnya menunjukkan efek yang dapat diabaikan. Menggunakan kerangka teori perbatasan kami berasumsi bahwa perilaku cyberloafing memiliki keterkaitan dengan usia dan status pernikahan karena dua alasan: pertama, usia terkait dengan pengelompokan generasi (misalnya Y dan Z) yang memang terbiasa beraktivitas menggunakan perangkat teknologi informasi. Chavan et al. (2021) mempertegas bahwa generasi milenial menganggap bahwa cyberloafing dianggap tidak membahayakan organisasi. Cyberloafing bahkan dianggap sebagai alat mereka untuk bekerja lebih cepat, untuk mengurangi kebosanan dan stres di tempat kerja. Kedua, menggunakan kerangka teori Border Theory bahwa karyawan memiliki dua kebutuhan social yaitu keluarga dan pekerjaan yang keduanya terkadang harus dipenuhi secara bersamaan. Terutama untuk karyawan yang sudah menikah, maka situasinya cenderung memiliki tuntutan yang lebih pribadi dan lebih cenderung memenuhi kebutuhan tersebut dengan melakukan cyberloafing selama jam kantor (Konig dan Caner de la Guardia, 2014; Koay et al., 2017). Tuntutan pribadi menurut definisi dapat disebut sebagai tuntutan keluarga atau sosial karyawan di luar pekerjaan (Konig dan Caner de la Guardia, 2014). Berdasarkan argumentasi teoritis tersebut maka hipotesis yang diajukan adalah:

H2: Usia dan status pernikahan berpengaruh signifikan terhadap perilaku cyberloafing H3. Usia dan status pernikahan memoderasi hubungan stres kerja dengan perilaku cyberloafing

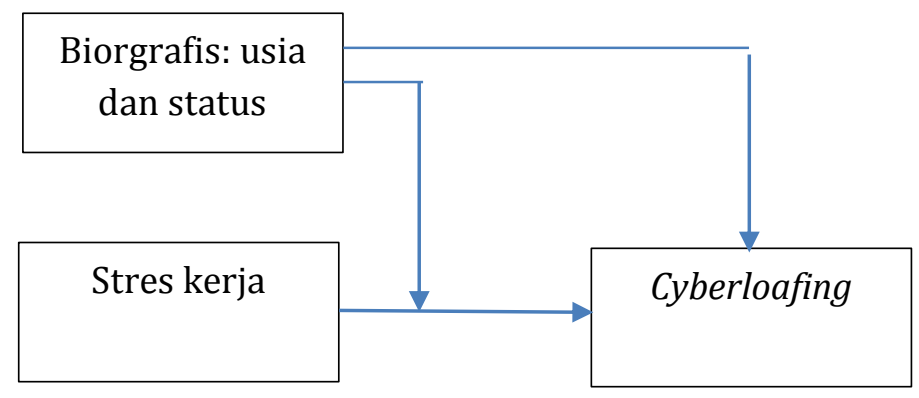

Gambar 1.

Model Penelitian yang digunakan 


\section{METODE}

\section{Prosedur Sampel}

Studi ini mengambil sampel mahasiswa yang berstatus bekerja di sebuah perguruan tinggi swasta di Jakarta. Data untuk penelitian ini dikumpulkan melalui metode survei online dengan meminta kesediaan sukarela responden untuk mengisi kuesioner. Teknik sampling yang digunakan dalah snowball sampling dimana perwakilan mahasiswa yang bekerja menyebarkan link kuesioner kepada rekan kerja mereka. Jumlah data final adalah sebanyak 182. Tabel 1 menampilan data mengenai karakteristik responden menunjukkan bahwa responden berdasarkan jenis kelamin relative seimbang dengan jumlah 52.2 persen wanita dan 47.8 persen laki-laki. Berdasarkan status pernikahan sebanyak 55.5 persen responden masih bersatus belum menikah, dan 44.5 persen berstatus sudah menikah. Usia responden berada di kisaran 22 - 38 tahun dengan ratarata usia adalah 29 tahun.

\section{Tabel 1.}

Karakteristik responden

\begin{tabular}{|c|c|c|}
\hline & Frekuensi & Persen \\
\hline \multicolumn{3}{|l|}{ Jenis Kelamin } \\
\hline Laki-Laki & 87 & 47.8 \\
\hline Wanita & 95 & 52.2 \\
\hline \multicolumn{3}{|l|}{ Status Pernikahan } \\
\hline Single & 101 & 55.5 \\
\hline Menikah & 81 & 44.5 \\
\hline \multicolumn{3}{|l|}{ Usia } \\
\hline Minimal & 22 & \\
\hline Maksimal & 38 & \\
\hline Mean & 29 & \\
\hline Std. dev & 5.28 & \\
\hline
\end{tabular}

Sumber: data lapangan (2020)

\section{Pengukuran}

Stres kerja diukur dengan menggunakan sembilan item yang dikembangkan oleh Jamal dan Baba (1992). Contoh item adalah "Saya sering merasa gelisah atau gugup sebagai akibat dari pekerjaan saya"; "Pekerjaan saya memberi saya lebih dari yang seharusnya". Internal konsistensi dengan Cronbach Alpha diperoleh sebesar 0.78. Cyberloafing diukur menggunakan skala Lim dan Teo (2005), yang terdiri dari 13 item seperti "seberapa sering anda mengunjungi situs web berita" dan "kunjungi situs web hiburan seperti youtube". Responden diminta memberikan rating dari 1 $=$ tidak pernah dan $5=$ sangat sering. Cronbach alpha untuk skala ini adalah 0.87 .

\section{Teknik analisis}

Studi ini menggunakan regresi hierarki moderasi dengan bantuan makro Process versi 3.5 yang dikembangkan oleh Hayes (2017). Analisis dilakukan dua kali menggunakan model 1 Process. Selain itu, pengujian hipotesis juga menggunakan pendekatan bootstrap seperti yang direkomendasi oleh Hayes (2017). 


\section{HASIL DAN PEMBAHASAN}

\section{Analisis deskriptif}

Tabel 2 berikut ini menampilkan analisis deskriptif dan korelasi antar variable. Hasil analisis menunjukkan bahwa stress kerja secara positif berkorelasi dengan cyvberloafing $(r=0.29$, p value < $0.01)$ dan negative dengan usia $(r=-0.20, p$ value $<0.05)$. Sementara itu, usia terbukti memiliki korelasi negative dengan cyber loafing $(r=-0.68$, $p$ value $<0.01)$ dan status pernikahan secara positif namun tidak signifikan berhubungan usia $(r=0.12, \mathrm{p}>0.05)$.

Tabel 2.

Deskripsi data dan korelasi antar variable

\begin{tabular}{clrrrrrr}
\hline No & Variable & Mean & SD & \multicolumn{1}{c}{1} & 2 & 3 & \multicolumn{1}{c}{4} \\
\hline $\mathbf{1}$ & Stres Kerja & 2.57 & 0.75 & 1 & & & \\
$\mathbf{2}$ & Cyberloafing & 3.02 & 0.88 & $.29^{* *}$ & 1 & & \\
$\mathbf{3}$ & Usia & 29.23 & 5.29 & $-.20^{* *}$ & $-.68^{* *}$ & 1 & \\
$\mathbf{4}$ & Status pernikahan & 1.45 & 0.50 & -.09 & -.09 & .12 & 1 \\
\hline
\end{tabular}

Sumber: Data olahan (2020), ${ }^{* *}=$ signifikan di level 1 persen

\section{Pengujian hipotesis}

Hasil analisis ditampilkan pada Tabel 3 menunjukkan bahwa hipotesis 1 yang menyatakan ada pengaruh positif stress kerja terhadap cyberloafing berhasil didukung untuk model 1 dan 2 ( $\beta=0.19$ dan 0.31 , $\mathrm{p}$ value $<0.01$ ). Selanjutnya hipotesis 2 yang menyatakan bahwa usia dan status pernikahan memiliki pengaruh terhadap cyberloafing hanya berhasil mendukung usia, sementara status pernikahan tidak terbukti signifikan mempengaruhi cyberloafing. Pengujian efek moderasi berdasarkan interaksi antara stress kerja dengan usia dan status pernikahan menunjukkan hanya interaksi 1 (stress kerja x usia) yang berhasil terdukung, sementara interaksi 2 (stress kerja x status pernikahan) tidak berhasil terdukung.

Tabel 3.

Pengujian hipotesis stress kerja terhadap cyberloafing (Makro Process model 1)

\begin{tabular}{|c|c|c|c|c|c|c|}
\hline \multirow[b]{2}{*}{ Variable } & \multicolumn{3}{|c|}{$\begin{array}{l}\text { Model 1: Usia sebagai } \\
\text { Moderator }\end{array}$} & \multicolumn{3}{|c|}{$\begin{array}{l}\text { Model 2: Status Pernikahan } \\
\text { sebagai moderator }\end{array}$} \\
\hline & $\beta$ & se & $\mathrm{p}$ & $\beta$ & se & $\mathrm{p}$ \\
\hline Constant & 3.00 & 0.05 & 0.00 & 3.01 & 0.06 & 0.00 \\
\hline Stres kerja & 0.19 & 0.06 & 0.00 & 0.31 & 0.08 & 0.00 \\
\hline Usia & -0.11 & 0.01 & 0.00 & & & \\
\hline Status pernikahan & & & & -0.13 & 0.13 & -0.31 \\
\hline Interaksi 1 & -0.02 & 0.01 & 0.04 & & & \\
\hline Interaksi 2 & & & & -0.30 & -1.78 & 0.08 \\
\hline $\mathrm{R} 2$ & 0.50 & & & 0.10 & & \\
\hline F-statistics & 58.93 & & & 6.76 & & \\
\hline
\end{tabular}

Sumber: Data olahan, Proces Macro versi 3.5

\section{Pembahasan}

Penelitian ini memberikan dua kontribusi substansial pada sisi teoritis mengenai penyebab cyberloafing. Pertama penelitian ini mendukung transactional model of stress (Lazarus \& Folkman, 1984) dimana cyberloafing merupakan konsekuensi dari stress kerja sehingga perilaku merupakan strategi 
koping untuk mengurangi efek negtif stress. Selain itu, studi juga mendukung temuan sebelumnya (Chavan et al., 2021; Henle \& Blanchard, 2008; Mercado et al., 2017; Pindek et al., 2018) yang memposisikan karyawan terlibat dalam cyberloafing untuk mengatasi pengalaman kerja yang membuat stres. Studi ini juga dalam posisi mendukung pernyataan Chavan et al. (2021) dan Mercado et al. (2017) yang menyatatakan cyberloafing sebagai mekanisme coping.

Kedua, hasil penelitian ini memberikan informasi mengenai bahwa usia memainkan peran penting dalam perilaku cyberloafing. Seperti ditunjukkan Tabel 4, efek stress kerja pada cyberloafing adalah sebesar 0.32 dan menurun secara drastic seiring dengan peningkatan usia. Kondisi ini juga menjelaskan mengapa status pernikahan tidak terkait dengan cyberloafing karena usia memiliki keterkaitan dengan status pernikahan. Oleh karena itu, penelitian tidak berhasil mendukung teori pembatasan (Clark, 2000) yang berasumsi bahwa individu yang memiliki peran ganda (misalnya sebagai ibu, ayah) akan cenderung melakukan cyberloafing untuk memenuhi kebutuhan pekerjaan dan keluarga secara bersamaan. Berlawanan dengan asumsi tersebut, usia dan status single justru memiliki kecenderungan yang leih besar melakukan aktivitas internet di jam kantor (misalnya menggunakan aplikasi Tiktok).

\section{Tabel 4.}

Efek moderasi usia pada hubungan stress kerja - cyberloafing

\begin{tabular}{|c|c|c|c|c|c|c|}
\hline \multirow{3}{*}{$\begin{array}{l}\text { Dependent } \\
\text { variable } \\
\text { Cyberloafing }\end{array}$} & \multicolumn{6}{|c|}{ Conditional Direct effect } \\
\hline & \multirow[t]{2}{*}{ Effect } & \multirow[t]{2}{*}{ se } & \multirow[t]{2}{*}{$\mathrm{t}$} & \multirow[t]{2}{*}{$\mathrm{p}$} & \multicolumn{2}{|c|}{$95 \% \mathrm{CL}$} \\
\hline & & & & & LL & UL \\
\hline Age (Low) & 0.32 & 0.09 & 3.44 & 0.00 & 0.14 & 0.50 \\
\hline Age (High) & 0.05 & 0.09 & 0.52 & 0.06 & -0.14 & 0.23 \\
\hline
\end{tabular}

Sumber: Data olahan, Proces Macro versi 3.5

Dari sisi praktis, studi ini juga memberikan dua kontribusi substansial pada praktik organisasi terkait dengan cyberloafing. Pertama, manajer perlu memberikan garis batas yang jelas mengenai aktivitas internet di jam kerja untuk kepentingan non-pekerjaan. Hal ini termasuk aturan penggunaan internet, smarphone, dan mengembangkan system pemantauan internet pada perangkat yang terhubung ke jaringan kantor. Namun, peraturan yang dibuat harus memiliki garis yang jelas dan mengecualikan situasi atau keadaan tertentu yang mengharuskan karyawan untuk menanggapi tuntutan pribadi yang mendesak dan penting, seperti menghubungi keluarga ketika harus bekerja lembur. Kedua, karena studi ini menemukan ada kaitan antara stress kerja dengan cyberloafing maka upaya untuk menguranginya adalah dengan mengurangi stress kerja karyawan. Selain itu, khusus untuk karyawan yang bekerja di bidang-bidang tertentu dapat dikecualikan. Misalnya karyawan bagian pemasaran yang menggunaan internet seperti menonton youtube mungkin merupakan cara mereka untuk memperoleh ide-ide baru.

\section{KESIMPULAN}

Dalam penelitian ini, kami menguji sttres kerja sebagai predictor cyberloafing. Dalam Studi 1, usia dijadikan pemoderasi hubungan stress kerja dan cyberloafing. Selanjutnya pada model 2, peran status pernikahan diperiksa untuk menguji hubungan yang sama. Hasil penelitian memberikan dukungan empiris pada hubungan stress kerja dan cyberloafing. Dua prediktor utama yaitu stress kerja dan usia ditemukan dapat memprediksi cyberloafing, sedangkan tidak untuk status pernikahan. Dua fungsi 
moderasi diuji dan memberikan hasil bahwa hanya usia yang dapat bertindak sebagai pemoderasi hubungan stress kerja dan cyberloafing. Prediktor menyumbang 50\% untuk model 1 dan 10\% untuk model 2 dari varians dalam cyberloafing.

\section{Keterbasan dan Saran}

Penelitian ini memiliki keterbatasan: pertama, sampel penelitian yang diambil tidak memgidentifikasi bagian/departemen tempat mereka bekerja sehingga tidak dapat memberikan implikasi praktis yang tepat bagi perusahaan. Kedua, desain pengambilan data yang dugunakan adalah cross-sectional yang berasal dari satu sumber untuk seluruh variable sehingga memiliki kemungkinan bias. Berdasarkan dua keterbatasan tersebut maka studi lanjutan dapat mereplikasi penelitian ini dengan mengindetifikasi lebih luas factor biografis seperti bidang kerja dan pendidikan, menggunakan desain longitudal, dan dapat meningkatkan analisis di level kelompok.

\section{REFERENSI}

Andel, S. A., Kessler, S. R., Pindek, S., Kleinman, G., \& Spector, P. E. (2019). Is cyberloafing more complex than we originally thought? Cyberloafing as a coping response to workplace aggression exposure. Computers in Human Behavior, 101, 124-130.

Derin, N., \& Gökçe, S. G. (2016). Are cyberloafers also innovators?: A study on the relationship between cyberloafing and innovative work behavior. Procedia-Social and Behavioral Sciences, 235, 694-700.

Hayes, A. F. (2017). Introduction to mediation, moderation, and conditional process analysis: A regression-based approach. Guilford publications.

Henle, C.A. and Blanchard, A.L. (2008), Correlates of different forms of cyberloafing: the role of norms and external locus of control, Computers in Human Behaviour, 24(3), 1067-1084

Jamal, M. and Baba, V.V. (1992), Shiftwork and department-type related to job stress, work attitudes and behavioral intentions: a study of nurses, Journal of Organizational Behavior, 13(5), 449-464.

Kim, S.J. and Byrne, S. (2011), Conceptualizing personal web usage in work contexts: a preliminary framework, Computers in Human Behaviour, 27(6), 2271-2283.

Kim, S. (2018). Managing Millennials' Personal Use of Technology at Work."Business Horizons 61 (2): 261-270. Accessed November 2, 2018. https://www-sciencedirectcom. simsrad.net.ocs.mq.edu.au/science/article/pii/S0007681317301623.

Kim, K., M. Triana, K. Chung, and N. Oh. (2016). When do Employees Cyberloaf? An Interactionist Perspective Examining Individual Differences, Justice, and Empowerment. Human Resource Management 55 (6): 1041-1058. doi:10.1002/hrm.21699.

Koay, K. Y., Soh, P. C. H., \& Chew, K. W. (2017). Do employees' private demands lead to cyberloafing? The mediating role of job stress. Management Research Review. 40(9), 10251038. https://doi.org/10.1108/MRR-11-2016-0252

Koay KY., Soh P.CH. (2019) Does Cyberloafing Really Harm Employees' Work Performance?: An Overview. In: Xu J., Cooke F., Gen M., Ahmed S. (eds) Proceedings of the Twelfth International Conference on Management Science and Engineering Management. ICMSEM 2018. Lecture Notes on Multidisciplinary Industrial Engineering. Springer, Cham. https://doi.org/10.1007/978-3-319-93351-1 71

Konig, C.J. and Caner de la Guardia, M.E. (2014), Exploring the positive side of personal internet use at work: does it help in managing the border between work and nonwork?, Computers in Human Behavior, 30, 355-360 
Lazarus, R. S., \& Folkman, S. (1984). Stress, appraisal, and coping. Springer publishing company.

Lim, P. K., Koay, K. Y., \& Chong, W. Y. (2020). The effects of abusive supervision, emotional exhaustion and organizational commitment on cyberloafing: a moderated-mediation examination. Internet Research.

Lim, V. K. (2002). The IT way of loafing on the job: Cyberloafing, neutralizing and organizational justice. Journal of organizational behavior: the international journal of industrial, occupational and Organizational Psychology and Behavior, 23(5), 675-694.

Lim, V. and Teo, T. (2005), "Prevalence, perceived seriousness, justification and regulation of cyberloafing in Singapore: an exploratory study", Information and Management, Vol. 42 No. 8, pp. 1081-1093.

Mercado, B. K., Giordano, C., \& Dilchert, S. (2017). A meta-analytic investigation of cyberloafing. Career Development International. 22(5), 546-564. https://doi.org/10.1108/CDI-08-2017$\underline{0142}$

Mastrangelo, P.M., Everton, W., and Jolton, J.A., (2006). Personal use of work computers: distraction versus destruction. CyberPsychology and Behaviour, 9,730-741.

Pindek, S., Krajcevska, A., \& Spector, P. E. (2018). Cyberloafing as a coping mechanism: Dealing with workplace boredom. Computers in Human Behavior, 86, 147-152.

Rahimnia, F., \& Mazidi, A. R. K. (2015). Functions of control mechanisms in mitigating workplace loafing; evidence from an Islamic society. Computers in Human Behavior, 48, 671-681.

\section{PROFIL PENULIS}

Dr. Achmadi adalah dosen tetap di Sekolah Tinggi Ilmu Ekonomi Tunas Nusantara. Fokus penelitian saat ini adalah kepemimpinan, ketidakamanan kerja, dan marketing strategic. 
This page intention to blank... 